\title{
DESIGNING THE SIRUCTURE OF SEEDBED USAGE FOR THE FARMS OF GRAIN AND HUSBANDRY SPECIAUZATION
}

Во многих регионах России и Иркутской области в частности для основного производственного типа хозяйств зерно-животноводческой специализации какой-либо методики по оптимизации отраслей растениеводства и животноводства не было.

Предложенная методика позволяет самим товаропроизводителям на основе нормативных расчетов обеспечить оптимальную нагрузку животных на пахотные земли, установить размер площадей под кормовые культуры, на товарные и другие цели.

В основу методики положена первоначальная задача обеспечения поголовья животных кормами по научно обоснованным рационам кормления с учетом их продуктивности, что является крайне актуальной задачей при планировании производства кормов.

Взаимосвязь между двумя основными отраслями (растениеводством и животноводством) ведется через кормопроизводство. Для жестких условий Сибири в целом, где «9 месяцев зима, остальное лето», вести земледелие (в узком смысле - растениеводство) крайне нерационально, так как без животноводства не может быть постоянного поступления финансовых ресурсов в течение года, а следовательно, устойчивого кадрового состояния и инфраструктуры, исключаются лучшие предшественники (а это кормовые культуры). Увлечение некоторых хозяйств чаще зерновым производством неизбежно ведет к высокой доле чистых паров (до 50 \%), к зернопаровой системе земледелия и истощению почв.

Ключевые слова: методика, рацион, структура использования пашни, специализация, кормовая единица.
In many regions of Russia, on the whole, and in the Irkutsk region, in particular, for basic industrial type of farms specialized in grain production and animal husbandry there were no methods on optimization of plant growing and cattle breeding branches.

The proposed methodology enables commodity manufacturers themselves, basing on standard calculations, to provide optimal load of animals on arable lands, to set up the amount of areas under forage crops, for commercial and other purposes.

The methodology is based on the initial task to provide animal herd with forages on scientifically based rations of feeding with the account of their productivity which is extremely actual task in planning fodder production.

Interrelation between two main branches (crop production and animal husbandry) is supported through fodder production. For severe conditions of Siberia, on the whole, where «9 months are winter, the rest ones - summer» to keep arable farming (plant growing, in narrow sense) is highly irrational, as without cattle breeding there cannot be constant incoming financial resources during the year, and consequently steady staff state and infrastructure, the best predecessors are excluded (but these are fodder crops). The excess interest of some farms in grain production more often inevitably leads to high share of bare fallows (up to $50 \%$ ), grain-fallow system of arable farming and soil depletion.

Key words: methods, ration, structure of seedbed use, specialization, feed unit.
Сметанина Олеся Викторовна -

кандидат сельскохозяйственных наук, старший научный сотрудник лаборатории земледелия ФГБНУ «Иркутский научно-исследовательский институт сельского хозяйства»

г. Иркутск

Тел.: 8(83952)69-84-31

E-mail: gnu iniish@mail.ru

\section{Солодун Владимир Иванович -}

доктор сельскохозяйственных наук, заведующий лабораторией земледелия ФГБНУ «Иркутский научноисследовательский институт сельского хозяйства» г. Иркутск

Тел.: 8(83952)69-84-31

E-mail: gnu iniish@mail.ru

\section{Зайцев Александр Михайлович -}

кандидат сельскохозяйственных наук, старший научный сотрудник лаборатории земледелия ФГБНУ «Иркутский научно-исследовательский институт сельского хозяйства»

г. Иркутск

Тел.: 8(83952)69-84-31

E-mail: gnu iniish@mail.ru
Smetanina Olesya Viktorovna -

Ph.D of Agricultural Sciences,

Senior Researcher of the Laboratory of Agriculture

FSBSI «Irkutsk Research Institute

of Agriculture»

Irkutsk

Tel.: 8(83952)69-84-31

E-mail: gnu iniish@mail.ru

Solodun Vladimir I vanovic -

Doctor of Agricultural Sciences,

Head of the Laboratory of Agriculture

FSBSI «Irkutsk Research Institute of Agriculture» Irkutsk

Tel.: 8(83952)69-84-31

E-mail: gnu_iniish@mail.ru

\section{Zaytsev Aleksander Mikhaylovich -}

Ph.D of Agricultural Sciences,

Senior Researcher of the Laboratory of Agriculture FSBSI «Irkutsk Research Institute of Agriculture» Irkutsk

Tel.: 8(83952)69-84-31

E-mail: gnu_iniish@mail.ru 
Горбунова Мария Семеновна -

кандидат сельскохозяйственных наук, старший научный сотрудник лаборатории земледелия ФГБНУ «Иркутский научно-исследовательский институт сельского хозяйства»

г. Иркутск

Тел.: 8(83952)69-84-31

E-mail: gnu_iniish@mail.ru
Gorbunova Mariya Semenovna -

Ph.D of Agricultural Sciences,

Senior Researcher of the Laboratory of Agriculture

FSBSI «Irkutsk Research Institute of Agriculture»

Irkutsk

Tel.: 8(83952)69-84-31

E-mail: gnu_iniish@mail.ru
B заимосвязь между двумя основными отраслями (растениеводством и животноводством) ведется через кормопроизводство. Для жестких условий Сибири в целом, где «9 месяцев зима, остальное лето", вести земледелие (в узком смысле растениеводство) крайне нерационально, так как без животноводства не может быть постоянного поступления финансовых ресурсов в течение года, а следовательно, устойчивого кадрового состояния и инфраструктуры, исключаются лучшие предшественники (а это кормовые культуры). Увлечение некоторых хозяйств чаще зерновым производством неизбежно ведет к высокой доле чистых паров (до 50 \%), к зернопаровой системе земледелия и истощению почв.

Поэтому оптимальная взаимоувязка растениеводства и животноводства является базовым принципом при ведении сельского хозяйства, особенно в Сибири. К сожалению, до настоящего времени этот, по сути, главный закон ведения агропроизводства нашел выражение в очень обобщенном виде в научных рекомендациях, а простой и доступной методики, позволяющей самим товаропроизводителям оптимизировать эти пропорции, предложено не было. В данной статье предлагается такой методический подход и полная технология расчетов для оптимизации отраслей в хозяйствах растениеводческо-животноводческой специализации.

Структура использования пашни и посевов может разрабатываться как для уже действующих хозяйств с определенной площадью, а также для вновь создаваемых. Кроме того, есть целый ряд хозяйств, особенно фермерских, которые периодически или ежегодно приращивают новые земли. В большинстве случаев как в одних, так и в других хозяйствах оптимизация структуры землепользования должна вестись по разработанной нами методике в ежегодном режиме.

Например, в хозяйстве юго-восточного агроландшафтного района имеется: фуражных (дойных) коров - 402 головы, молодняка КРС (крупного рогатого скота) - 689 голов, лошадей взрослых - 9, молодняка лошадей - 32 головы, площадь пашни - 5135 га.

Планируется ежегодно доить 5000 литров молока от одной фуражной (условной головы). Задание: рассчитать потребность в кормах и определить посевные площади под кормовые культуры с учетом получения требуемых видов кормов и общую структуру использования пашни.

Вначале все виды животных и их половозрастные группы переводятся в условные головы [1] через коэффициенты перевода (табл. 1).

В нашем примере: 402 гол. • $1=402$ усл. гол., 689 • 0,6 = 413 усл. гол., 9 • 1 = 9 усл. гол., $31 \cdot 0,6=19$ усл. гол. Итого 844 условные головы.

Для получения молока 5000 л в год по зональным нормативам (табл. 2) понадобится 52 ц к. ед. в год на условную голову.

Рекомендуемый для этого рацион [2]: концентраты - 27,5\%; сено - 19,5\%; сенаж - 10,7\%; силос - 13,3 \%; корнеплоды - 8,2 \%; зеленые корма - 20,8 \%. На все поголовье потребуется 844 усл. гол. • 52 ц к. ед. $=43888$ ц к. ед.

Согласно рациону [3] это составит: концентраты (27,5 \%) - 12069 ц к. ед.; сено (19,5 \%) 8558 ц к. ед.; сенаж (10,7\%) - 4696 ц к. ед.; силос $(13,3 \%)$ - 5837 ц к. ед.; корнеплоды (8,2 \%) 3599 ц к. ед.; зеленый корм (20,8 \%) - 9129 ц к. ед. Итого - $100 \%$.

Далее необходимо перевести корма из кормовых единиц в натуральные показатели делением потребности видов кормов в кормовых единицах [4] на коэффициенты питательности кормов (табл. 3).

Таблица 1 - Коэффициенты пересчета (перевода) животных в условные головы

\begin{tabular}{|l|c|}
\hline \multicolumn{1}{|c|}{ Видживотных } & Коэффициент перевода \\
\hline Коровы, быки & 1,0 \\
\hline Остальное поголовье КРС & 0,6 \\
\hline Свиньи & 0,3 \\
\hline Овцы & 0,1 \\
\hline Лошади & 1,0 \\
\hline Молодняк лошадей & 0,6 \\
\hline Птица & 0,02 \\
\hline
\end{tabular}


Таблица 2 - Среднегодовая структура кормовых рационов молочного стада с учетом среднегодовой продуктивности 1 условной головы КРС

\begin{tabular}{|c|c|c|c|c|c|c|c|}
\hline \multirow[b]{2}{*}{$\begin{array}{c}\text { Среднегодовая } \\
\text { продуктивность, кг }\end{array}$} & \multicolumn{6}{|c|}{ В \% от общей потребности } & \multirow[b]{2}{*}{$\begin{array}{c}\text { Всего кормо- } \\
\text { вых единиц, } \\
\text { ц/га }\end{array}$} \\
\hline & Концентраты & Сено & Сенаж & Силос & Корнеплоды & $\begin{array}{c}\text { Зеленые } \\
\text { корма }\end{array}$ & \\
\hline 4000 & 22,8 & 19,2 & 11,6 & 15,3 & 7,6 & 23,5 & 48,0 \\
\hline 4200 & 24,6 & 19,5 & 11,1 & 14,5 & 7,7 & 22,6 & - \\
\hline 4500 & 25,4 & 18,7 & 10,9 & 14,4 & 8,4 & 22,2 & - \\
\hline 4800 & 27,1 & 20,2 & 10,5 & 12,9 & 7,9 & 21,4 & - \\
\hline 5000 & 27,5 & 19,5 & 10,7 & 13,3 & 8,2 & 20,8 & 52,0 \\
\hline 5200 & 27,9 & 18,8 & 10,9 & 13,8 & 8,8 & 19,8 & - \\
\hline 5500 & 31,6 & 18,0 & 11,9 & 11,7 & 8,6 & 18,2 & - \\
\hline 5800 & 33,9 & 17,2 & 12,0 & 10,8 & 9,0 & 17,4 & - \\
\hline 6000 & 34,1 & 16,7 & 13,4 & 11,1 & 8,5 & 16,2 & 65,0 \\
\hline 6200 & 36,5 & 16,4 & 13,0 & 9,9 & 8,5 & 15,7 & - \\
\hline 6500 & 37,5 & 16,6 & 12,6 & 9,3 & 8,6 & 15,4 & - \\
\hline 7000 & 38,5 & 17,8 & 12,5 & 9,1 & 8,2 & 13,9 & 70,0 \\
\hline 7500 и выше & 40,0 & 17,5 & 12,1 & 8,9 & 8,2 & 13,3 & - \\
\hline
\end{tabular}

Таблица 3 - Питательная ценность основных видов кормов

\begin{tabular}{|c|c|c|c|}
\hline Вид корма & Корм. ед., кг & Вид корма & Корм. ед., кг \\
\hline Зеленый корм & 0,18 & Сенаж в среднем & $0,24-0,30$ \\
\hline $\begin{array}{l}\text { В т. ч.: трава } \\
\text { естественных } \\
\text { угодий }\end{array}$ & 0,16 & Корнеплоды & 0,12 \\
\hline сеяных трав & 0,18 & Картофель & 0,28 \\
\hline рапс & 0,24 & $\begin{array}{l}\text { Комбикорма } \\
\text { (концентраты) }\end{array}$ & 0,97 \\
\hline Сено в среднем & $0,46-0,47$ & Овощи & 0,10 \\
\hline $\begin{array}{c}\text { В т. ч.: естественных } \\
\text { угодий }\end{array}$ & 0,48 & Молоко & 0,37 \\
\hline злаковых трав & 0,48 & Отходы пшеницы & 0,1 \\
\hline бобовых трав & 0,49 & Зерно & $1,0-1,05$ \\
\hline Солома в среднем & 0,20 & В т. ч.: пшеница & 1,017 \\
\hline Силос в среднем & $0,12-0,17$ & овес & 1,00 \\
\hline \multirow{3}{*}{\multicolumn{2}{|c|}{$\begin{array}{l}\text { Для расчетов возьмем следующие усред- } \\
\text { ненные коэффициенты: зерно (концентраты) - }\end{array}$}} & ячмень & 1,21 \\
\hline & & рапс & 1,18 \\
\hline & & горох & 1,17 \\
\hline
\end{tabular}

1,0; зеленая масса - 0,18; концентраты - 0,12. При необходимости зеленую массу всегда можно перевести в силос, сено, сенаж и наоборот.

В нашем примере в натуральных показателях это составит: концентраты - 12069 : 1,0 - 12069ц зерна; сено - $8588: 0,18=47711$ ц зеленой массы; сенаж - $4696: 0,18=26088$ ц зеленой массы; силос - $5838: 0,18=32433$ ц зеленой массы; корнеплоды - 3599 : 0,12 = 29992 ц корней; зеленая масса трав - $9129: 0,18=50716$ ц зеленой массы.

После этого делением натуральных показателей на урожайность (допустим, планируем зерна - 25 ц/га, зеленой массы на силос, сено, сенаж - 100 ц/га, корнеплодов - 200 ц/га) определяем посевные площади.

Под концентраты потребуется: 12069 ц : 25 ц/га = 483 га + $10 \%$ страхфонд = 531 га. Под зеленую траву на сено: 47711 ц : 100 ц/га = 477 га +
+ 15 \% страхфонд = 549 га. Под зеленую массу на сенаж: 26088 ц : 100 ц/га = 261 га + $15 \%$ страхфонд = 300 га. Под зеленую массу на силос: 32433 ц : 100 ц/га = 324 га + 15 \% страхфонд = 393 га. Под корнеплоды: 29992 ц : 200 ц/ га $=150 г а+15 \%$ страхфонд = 173 га. Под зеленый корм: 50715 ц : 100 ц/га = 507га + 15 \% страхфонд = 522 га. Итого под кормовые потребуется без зерновых 1917 га, с зерновыми - 2448 га.

С учетом рекомендуемой [5] для данного агроландшафтного района доли паров $15 \%$ - 770 га (табл. 4) под кормовые и чистый пар потребуется 2687 га. К этой площади следует добавить потребность в площадях для производства семян, внутрихозяйственных нужд. 
Таблица 4 - Адаптивная структура использования пашни по 8 агроландшафтным районам Иркутской области, \%

\begin{tabular}{|c|c|c|c|c|c|c|c|c|}
\hline \multirow[b]{2}{*}{$\begin{array}{c}\text { Элемент } \\
\text { структуры пашни }\end{array}$} & \multicolumn{8}{|c|}{ Агроландшафтный район } \\
\hline & 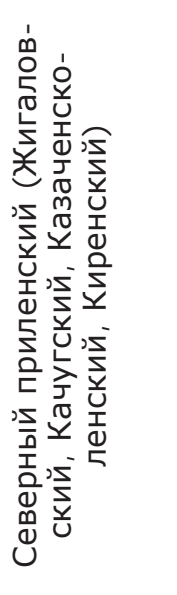 & 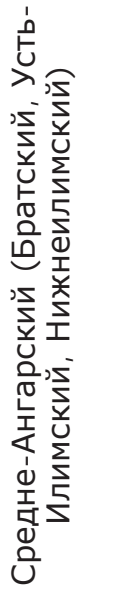 & 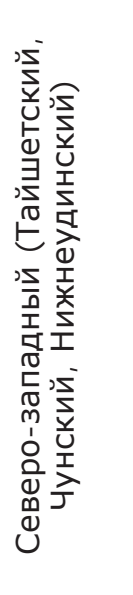 & 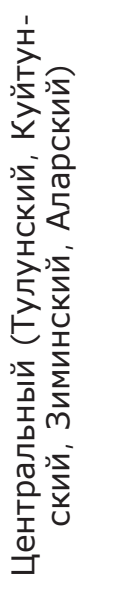 & 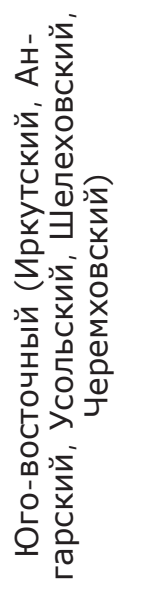 & 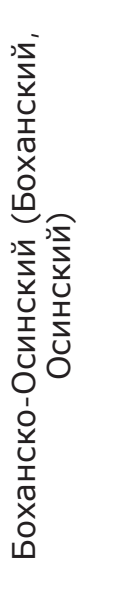 & 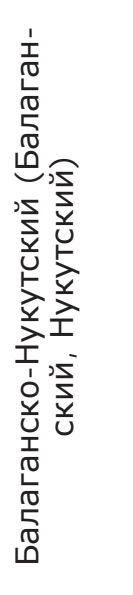 & 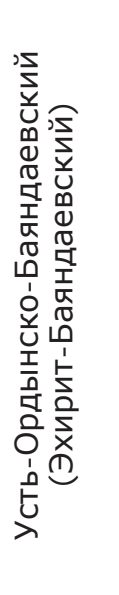 \\
\hline $\begin{array}{l}\text { 1. Зерновые } \\
\text { и зернобобовые }\end{array}$ & $46-48$ & $48-50$ & $50-52$ & $46-48$ & $44-46$ & $48-50$ & $53-55$ & $49-51$ \\
\hline $\begin{array}{l}\text { 2. Картофель, } \\
\text { овощи, крупяные }\end{array}$ & $0,5-1,5$ & 1,3 & $2-4$ & $3-5$ & $4-6$ & $1-2$ & $\begin{array}{l}0,5- \\
1,2\end{array}$ & $\begin{array}{l}0,5- \\
1,5\end{array}$ \\
\hline 3. Кормовые & $34-36$ & $32-34$ & $28-30$ & $33-35$ & $34-36$ & $28-30$ & $25-27$ & $29-31$ \\
\hline 4. Пары & $15-17$ & $18-20$ & $17-19$ & $12-14$ & $10-15$ & $20-22$ & $23-25$ & $22-24$ \\
\hline Итого & 100 & 100 & 100 & 100 & 100 & 100 & 100 & 100 \\
\hline
\end{tabular}

Сравнивая расчетные показатели с фактическими площадями пашни, в хозяйстве вводятся соответствующие коррективы, если фактическая площадь превышает расчет, то остаток пашни используют, например, для производства зерна, если меньше - необходимо сократить поголовье и т. д. В конечном итоге, моделируя разные варианты, придерживаются научно обоснованной структуры пашни, рекомендованной для хозяйств данной специализации, представленной в вышеприведенной таблице 4. В нашем расчете полученные показатели совпали с фактической площадью пашни, а именно: площадь под зерновыми -
2448 га, под кормовыми - 1917 га, под паром 770 га. Итого - 5135 га.

Разработанная методика позволяет обеспечить имеющееся или плановое поголовье животных полным набором кормов по научно обоснованным нормам и взаимоувязку отраслей через структуру пашни, посевов, создавая допустимую нагрузку скота на пашню при реальной продуктивности пашни и животных.

Работа выполнена в рамках Государственного задания ФАНО России (проект № 0806-20180002).

\section{Литература}

1. Сафонов А. Ф., Платонов И. Г. Методика разработки адаптивно-ландшафтных систем земледелия Нечерноземной зоны. М. : Издательство МСХА, 2001. 104 с.

2. Солодун В. И., Горбунова М. С. Системы земледелия : учебно-методическое пособие по выполнению практических занятий. Иркутск : Издательство ИрГСХА, 2014. 132 c.

3. Нормы и рационы кормления сельскохозяйственных животных : справочное пособие / А. П. Калашникова, В. И. Фисина, В. В. Щеглова, Н. И. Клейменова. 3-е изд., перераб. и доп. М., 2003. 456 с.

4. Щеглов В. В., Боярский Л. Г. Корма: приготовление, хранение, использование :

\section{References}

1. Safonov A. F., Platonov I. G. Methodology of elaborating adaptive-landscape systems of arable farming in Non-black soil zone. M. : publishing MAA, 2001. $104 \mathrm{p}$.

2. Solodun V. I., Gorbunova M. S. Systems of arable farming : training and methodical handbook on making practical tasks. Irkutsk: publishing ISAA. 2014. 132 p.

3. Standards and rations of feeding farm animals : reference book / A. P. Kalaschnikova, V. I. Fisina, V. V. Shcheglova, N. I. Kleymenova. 3rd edition, revised and expanded. M., 2003. $456 \mathrm{p}$.

4. Shcheglov V. V., Boyarskiy L. G. Forages: preparation, storage, usage : handbook. M. : Agropromizdat, 1990. 255 p. 
справочник. М. : Агропромиздат, 1990. 255 c.

5. Солодун В. И. Методические рекомендации по разработке оптимальной структуры использования пашни и повышению её плодородия в земледелии Иркутской области. Иркутск : Облинформпечать, 1993. $31 \mathrm{c}$.
5. Solodun V. I. Methodical recommendations on the elaboration of optimal structure of seedbed use and raising its fertility in arable farming of the Irkutsk region. Irkutsk : Oblinformpechat, 1993. $31 \mathrm{p}$. 